improvement, are stressed. In contrast, the replacement policy in the 9 French A.I. centers appears to be similar to that prevailing under commercial conditions, with average of 20 months of age for A.I. boars in service. This leads pedigree breeders to pick-up the youngest ones of those for insemination in their herds. Also, from a strictly commercial viewpoint, a fast replacement of A.I. boars should be recommended. Considering one year as a maximal length of use, it appears that about half of the French A.I. boars do not satisfy that requirement.

\title{
Selection for prolificacy in the pig : response to selection in an open line
}

\author{
G. BOLET ${ }^{(1)}$, Christine RENARD ${ }^{(2)}$, L. OLLIVIER ${ }^{(3)}$, P. DANDO ${ }^{(4)}$ \\ Institut National de la Recherche Agronomique \\ (1) Station d'Amélioration Génétique des Animaux, B.P. 27, 31326 Castanet-Tolosan. \\ (2) INRA-C.E.A., Laboratoire de Radiobiologie appliquée, 78350 Jouy-en-Josas. \\ (3) Station de Génétique quantitative et appliquée, 78350 Jouy-en-Josas. \\ (4) Domaine expérimental de Bourges, 18520 Avord.
}

After 10 generations of selection for litter size (on 1st) and $2^{\text {nd }}$ litter in a closed line (as previously reported by Ollivier \& Bolet, 1981, Ann. Zootech., 30, 382), the selection line (S) have been opened to the progeny of highly prolific sows and of the "hyperprolific " boars of Rouillé (see Legault \& Gruand, 1976, Ann. Zootech., 25, 445). The rate of immigration into the $\mathrm{S}$ line has been about $1 / 8$ per generation, and, simultaneously, selection has been carried on within $\mathrm{S}$, on 1st litter size. The genetic level of the 16th generation ( $\mathrm{S} \mathrm{16)}$ has been assessed through a comparison to a cross (CR) between S 14 females and control line boars (C), whose semen had been frozen 5 years before. This comparison, which includes the first 3 litters of $69 \mathrm{~S} 16$ and $72 \mathrm{CR}$ gilts put to mating, has shown a significant advantage of $\mathrm{S} 16$ in prolificacy. The genetic gain, estimated under some given assumptions, is 1.7 piglets born/litter above the $\mathrm{C}$ line. As the genetic gain due to immigration can be estimated, given the immigration rate and an assumed genetic level of the immigrants, it appears that whithin-line selection should account for more than half of the total genetic gain. However, in spite of the proven superiority of the " hyperprolific " line for ovulation rate, the advantage of the $S$ line over $C$ (about 2 corporea lutea, as evaluated in the 4th gestation) does not seem to have increased since the 10 th generation. On the other hand, $S 16$ appears to be significantly leaner than $\mathrm{C}$. This is a probable consequence of immigration, through which the $\mathrm{S}$ line has benefited from the genetic gain in leanness realized on the farms providing the hyperprolific sows. The haplotypes of the major histo-compatibility complex (SLA) identified in S16 as compared to CR show that selection has exerted a negative effect on SLA polymorphism.

\section{Evaluation of the "hyperprolific " line of large white boars in herds of the Poitou area}

\author{
Pascale LE ROY ${ }^{(1)}$, C. LEGAULT $^{(1)}$, J. GRUAND ${ }^{(2)}$ \\ Institut National de la Recherche Agronomique \\ (1) Station de Génétique quantitative et appliquée, 78350 Jouy-en-Josas. \\ (2) Station Expérimentale de Sélection Porcine, 86480 Rouillé.
}

This study deals with the results of a selection experiment on prolificacy conducted since 1973 at the Experimental Station for Artificial Insemination in Rouillé. The objective was to create a line of so-called «hyperprolific » Large White boars $(\mathrm{H})$ by applying a very intense selection among sows of that area. The criterion of selection was $D=n d /[1+0.15(n-1)]$, with $d$ being the average phenotypic superiority for total number of piglets born in $\mathbf{n}$ litters. The response to selection was evaluated in commercial farms of the Poitou area through comparing sows sired by boars from the $\mathrm{H}$ line and contemporary sows sired by boars from an other Large White line 
considered as control (c). The low heritabılity estimate for the dam-daughter pathway $\left(\mathrm{h}^{2}=.02 \pm .03\right)$ suggests that unfavourable maternal effects exist. In contrast, the realized heritability estimated for the paternal pathway is higher $\left(h_{r}=.14 \pm .05\right)$. The latter parameter allows to assess the overall efficiency of the breeding scheme for $D=12$ on average, an advantage of 0.84 piglets born and .60 piglets born alive per litter was established by the daughters of $H$ boars. The overall economic gain resulting from this genetic progress in prolificacy is expected to be about $5 \%$ in a herd using boars from the $\mathrm{H}$ line. However, a lower heritability was found for $1 \mathrm{st}$ parity litter size whereas genetic correlations between successive litter sizes were markedly less than unity. The possible causes for these differences and the consequences on the breeding policy are discussed.

\title{
II. - REPRODUCTION
}

\section{Recent advances in boar semen storage technology}

\author{
M. PAQUIGNON ${ }^{(1)}$, J. BUSSIĖRE ${ }^{(2)}$, F. BARITEAU ${ }^{(2)}$ \\ (1) Institut Technique du Porc, M.N.E., 149, rue de Bercy, 75595 Paris Cedex XII. \\ (2) INRA-S.E.I.A., 86480 Rouillé.
}

This review makes a general survey of techniques used for the preservation of semen in the liquid or frozen state.

As regards storage in the liquid state several extenders have been developed to preserve the fertilizing capacity of semen for several days. In order to obtain the highest conception rate and prolificacy, it seems necessary in the present state of our knowledge to use the total fraction of ejaculate and to extend semen in B.T.S. to obtain $3 \times 10^{9} \mathrm{spz} / 100 \mathrm{ml}$. In such conditions, the fertilizing capacity is preserved up to 3 days after collection without reduction in conception rate and prolificacy.

As regards storage of deep-frozen semen, several methods have been developed. Semen quality after thawing varies according to the freezing-thawing extenders used and to the techniques of preparation and storage. Analysis by electronic microscopy, after cryosubstitution, of spermatozoa and their environment shows that their dehydratation at freezing is an important factor for the preservation of semen quality after thawing, at least as regards the acrosome integrity. Results of artificial inseminations performed during the last 10 years do not show a difference between straws and pellets concerning the farrowing rate and prolificacy. However, other factors such as insemination period, inseminator and boar may affect fertility. In conclusion, frozen semen used for A.I. can be expected to result in a conception rate 20 to $30 \%$ lower and in a litter size about 1 to 3 piglets smaller than does fresh semen.

\section{Comparison of different techniques of storage of boar semen. Effect on fertilization mechanisms}

\author{
Laurence LWOFF ${ }^{(1)}$, Jacqueline BEZARD ${ }^{(1)}$, M. PAQUIGNON ${ }^{(2)}$
}

(1) INRA, Station de Physiologie de la Reproduction, Nouzilly, 37380 Monnaie. (2) Institut Technique du Porc, M.N.E., 149, rue de Bercy, 75595 Paris Cedex XII.

An experiment was made to compare the effect of using semen stored in the liquid or frozen state on fertilization mechanisms. Twenty four sows distributed into 4 groups were inseminated 